\title{
PRIMEIROS ENCONTROS COM A ANTROPOFAGIA AMERÍNDIA: DE COLOMBO A PIGAFETTA
}

\author{
POR \\ PEDRo FonseCa \\ University of Missouri-Columbia
}

Em seu compreensivo estudo sobre as perspectivas de apreensão narrativa da realidade fisica e humana das terras do Novo Mundo, visitadas por viajantes e cronistas europeus no século XVI sob a égide das navegações ibéricas, notadamente espanholas, Antonello Gerbi (1985, 124-25), após sumarizar as primeiras contribuiçð̃es documentais desses "incipientes" historiadores, conclui que "[a]ny attempt to trace a line of development from Columbus to Oviedo is completely illusory, indeed misleading." Imediatamente após esta observação, resume à guisa de avaliação, as razões que justificam essa impossibilidade: ausência de uniformidade lingǘstica, diferença de interesses mentais e ângulos visuais, falta de intenção científica e de caráter sistemático, heterogeneidade na natureza dos sentimentos (vantagem pessoal, lucratividade, vaidade, adulação apologética, sensacionalismo jornalístico, deleite narrativo, especulação mercantilista); discrepâncias estas que se estendem à figura do nativo, ora louvado ora depreciado.

Epistemologicamente, segundo Gerbi, a impossibilidade desse legado cronístico em oferecer uma progressão do conhecimento histórico da natureza americana reside no fato de

\begin{abstract}
the dozen or so most important authors do not form a chain of scholars, handing on their findings and interpretations from one to another. To all intents and purposes, in fact, apart from the odd exception (Peter Martyr ...) they are completely unaware of each other. They address themselves to different public and certainly do not feel called upon to back up their descriptions - almost invariably of 'things never seen before' - with precedents and corroborating testimony.... Each is his own authority, even when, by chance or necessity, what he relates tallies with other accounts. Viewed from the distance of several centuries they look like solitary scouts or reconnaissance patrols, sailing or galloping, along diverse paths, toward the unknown heart of the continent.
\end{abstract}

Em 1978, curiosamente quase coincidente com a data do livro de Gerbi $\longrightarrow$ autor publica originalmente em italiano La natura delle Indie Nove: Da Cristoforo Colombo a Gonzalo Fernández de Oviedo em 1975,- - Hayden White (1992, 150-82) em seu seminal ensaio sobre as formas de conceituação arqueológica da noção do homem selvagem, comentando sobre o seu método de análise utilizado —o estudo de White compreende vestígios do pensamento arcaico (antigüidade clássica e hebraica) e medieval sobre o 
assunto-, esclarece que a sua abordagem será sobretudo a de uma interpretação dos arquétipos míticos que embasam o tema até a sua derivação moderna no conceito de Noble Savage, devendo oferecer finalmente um repositório de idéias que

will look more like an archaeologist's cabinet of artifacts than the flowing narrative of the historian; and we shall probably come to rest with a sense of structural stasis rather than with a sense of the developmental process by which various ideas came together and coalesced to produce the Noble Savage of the eighteenth century. What I provide here is little more than the historian's equivalent of a field archaeologist's notes, reflections on a search for archetypal forms rather than an account of their variations, combinations, and permutations during the late medieval and early modern ages. (150-51)

Tendo-se em vista a conclusão de Gerbi sobre a dificuldade em se estabelecer uma concordância opinativa acerca do nativo nos primeiros relatos da América e a teoria arquetípica de White, o presente ensaio procurará situar o estudo da natureza ameríndia num campo intermediário entre a sistematização histórica e o estudo temático, procurando inventariar naqueles relatos passagens em que a antropofagia é observada ou comentada, a fim de se sugerir especulações interpretativas sobre a disposição mental e formação cultural com as quais tais escritores possivelmente teriam abordado o fenômeno e ressoado características do contexto ideológico do momento histórico-cultural em que se inserem. Para tanto, e refletindo-se preliminarmente sobre as observações de Gerbi acerca da relativa ausência de intertextualidade entre os primeiros relatos da América, objetiva-se neste ensaio captar a informação que se crê original e sem influências disseminativas. Se por um lado isto desfavorece o tratamento histórico como visão continuada do conhecimento, por outro permite apreciar o impacto de percepçð̃es que, justamente por seu insulamento informativo podem revelar, quando confrontadas, a possibilidade de verificação de aspectos comuns à construção ideária desses relatos anteriores às intentadas canonizações de estilo e visão em autores oficiais como Pedro Mártir e Oviedo, que apesar do seu meritório esforço organizador da imensa quantidade de conhecimento sobre o Novo Mundo, ainda assim o seu compromisso uniformizador incapacita-se no estabelecimento definitivo da vasta e ainda inabarcável realidade de um continente parcialmente explorado ou conjecturado. ${ }^{1}$ Sendo esta uma justificativa, tais autores serão aqui mencionados como referências indiretas, mesmo porque, dada a voluminosidade da sua obra, merecem específico tratamento à parte.

Assim, selecionou-se como corpus efetivo deste ensaio os escritos de Colombo, Alvarez Chanca, Michele da Cuneo, Amerigo Vespucci, Martín Fernández de Enciso e Francescantonio Pigafetta, reservando-se ao outro Vespucci e a Nicoló Scillacio um papel secundário em virtude dos seus escritos serem considerados como recriações; frutos de uma experiência indireta na obtenção do conhecimento que relatam. No caso de Colombo,

\footnotetext{
' O próprio Gerbi (257) identifica a consciência que Oviedo tem em supor-se incapaz de descrever em completude a realidade americana "[a]s he sets out on the third part of the History ... [quando] gloomly confesses his feelings of inadequacy before a world so vast and stupefying: 'I well know that I am at the end of my life, and I find myself only just approaching the substance of the great and innumerable secrets about to be revealed in the second hemisphere ..."
} 
apesar da polêmica levantada acerca da adulterabilidade dos seus documentos, teve que se contar necessariamente com o provento editorial a que se submeteram os seus originais. Com relação à possibilidade de inclusão neste ensaio de relatos especificamente escritos por autores portugueses referentes ao Brasil, registra-se aqui a sua omissão por razões não só de sua escassa existência (Gibbon 1972,378$)^{2}$ mas ainda devido à sua insuficiente repercussão e difusão não só na época mas também na posteridade.

Uma abordagem da antropofagia, mesmo na sua modernidade histórica, como no caso do nativo americano, implica a necessidade do reconhecimento, ainda que superficial, da sua presença a partir de Hesíodo (Athanassakis 1983, 1-11), o primeiro poeta grego a tratar teogônica e cosmologicamente do tema na Teogonia, composta provavelmente por volta do último quartel do século VIII a.C. ${ }^{3}$ Isto para se situar, dada a vastidão do assunto disperso nas mais variadas culturas primitivas e históricas, apenas na tradição ocidental. Em os Ciclopes de Eurípedes, escritos quase certamente pouco depois de 411 a.C., o tema da antropofagia polifêmica de caráter hedonístico comparece tratado na modalidade dramática originária do culto dionisíaco. ${ }^{4} \mathrm{Se}$ a antropofagia clássica - também presente em outros autores da Antigüidade greco-romana tais como Heródoto, Accius e Ovídio - ainda encontra-se correspondida a sofisticados motivos sacrificiais envolvendo a mitologia, em Sêneca, o seu tratamento, na agônica e estóica tragédia Thyestes (escrita no século I), resulta da utilização do conceito como instrumento de uma deliberada paixão de vingança e poder contextualizados sócio-historicamente. ${ }^{5}$

Outro ponto de observação obrigatória, na evolução do tratamento antropofágico na literatura ocidental, é a sua comum derivação para a modalidade crítica e analítica (Mayor 1888, 2: $355 \mathrm{ff}$.) que além, de Juvenal, representa-se no Satyricon de Petrônio, escrito por volta da segunda metade do século I e cujo humor cômico parece ter-lhe sido sugerido como preferência da corte neroniana. ${ }^{6}$ Deslocada no loci classici da sua original motivação mitológica (e ainda presente em autores como Horácio, Marcial e Tácito), a antropofagia, quer submetida à seriedade trágica, poética ou realista, quer utilizada de maneira crítica, satírica, fársica ou cômica, parece, entretanto, constituir-se numa modalidade externalmente estruturada com intenções analógicas orientadas a outros conteúdos. Ainda no decorrer

2 "[T] deplores the negligence of the kings of Portugal, who should have required and preserved the fresh memorials of each successful expedition."

${ }^{3} \mathrm{O}$ elucidativo estudo introdutório e notas de Athanassakis parecem definitivos para 0 estabelecimento da bio-bibliografia e do contexto histórico-cultural de Hesíodo.

${ }^{4}$ Sobre o caráter antitético da antropofagia em Eurípedes - uma combinação da selvageria primitiva de Homero com a prática sacrificial sofisticada dos ciclopes-, ver Seaford (1984, 53-54).

${ }^{5}$ Para a contextualização trágica do nihilismo teogônico e cívico de Sêneca, em referência à época da devassidão moral e corrupção de valores sociais e humanos em que viveu o autor, ver Slavitt (1992, viii-xiv, 71-72).

${ }^{6} \mathrm{O}$ aproveitamento anti-heróico e mimeticamente inferior do tema da antropofagia no Satyricon é estudado (Rose 1971, 39-41) em referência ao conhecido episódio do Testamento de Eumolpus (fr. 141.2). Sobre o realismo hipócrita, incitador à prática antropofágica, com referências escabrosas e macabras, do episódio de Eumolpus, ver Sullivan $(1968,76)$. 
do século I, o tema é desenvolvido em direção a especulações generalizantes que investigam o seu conhecimento para além do campo especificamente literário. Em Tácito, por exemplo, o assunto torna-se apreciado sob o ponto de vista histórico-civilizacional. Entretanto, é com a História Natural de Plínio (23-79 d.C.) que a antropofagia, ao lado de outras noçðes pré-científicas sobre a natureza física e humana, adquire um especial interesse e curiosidade a repercutirem em gerações posteriores. Para se avaliar, ainda que de passagem, a enorme repercussão dessa compósita obra (Turner 1962,9$),{ }^{7}$ há que se considerar pelo menos alguns traços marcantes da disposição mental do autor que

seems to have lived in a permanent state of astonishment. ... convinced that the world around him was a most extraordinary place, chock-full of fantastic things. The result was that he instinctively accumulated all the most sensational 'facts,' theories, and anedoctes in circulation, not because he meant to be a sensational writer, but because such material tallied his romantic [sic] preconceptions of the nature of reality. Thus the Natural History became a vast repository of statements which nearly always appeal to the imagination, however much they revolt common sense.

Justamente por seu caráter de curiosidade a-científica e acúmulo enciclopedístico de portentos e fabulosidades é de se crer que Plínio tenha influenciado principalmente a mentalidade da Idade Média, e ainda segundo Turner (16):

[p]erhaps the oddest result of Pliny's zoology is the medieval bestiary, an allegorical form which flourished from the fifth to the fifteenth century. From his anthropology the most shameless piece of borrowing occurs in Mandeville's Travels, Sir John, the supposed traveller, is giving an eye-witness account of the inhabitants of Ethiopia: 'In that contree ben folk that han but o foot; and thei gon so blyve that it is mervaylle; and the foot is so large that it schadeweth all the body agen the sonne, whan they wole lye and reste hem.'

A irrestrita simpatia pelas narrativas de Plínio, disseminadas e refundidas na medievalidade, atinge especial importância como fonte de sugestões pervasivas à disposição e energia mental com as quais os primeiros navegantes europeus aportaram e visionaram a percepção da surpreendentemente nova realidade americana, principalmente a constituída pela natureza, aspecto físico, hábitos e costumes dos ameríndios. Os fenômenos e portentos zoomórficos e antropomórficos da História Natural vieram corresponder à concepção e imaginação da existência de distantes povos selvagens e primitivos em remotas partes do globo, não só pela sua simples provisão de descrições e ingeniosas explicações, mas, principalmente, porque o seu conteúdo de informações e conhecimentos inventariados vieram satisfazer o estado sócio-cultural —se não propriamente da cultura oficial—, pelo menos da grande maioria da sociedade européia medieval numa época em que o

${ }^{7} \mathrm{O}$ livro de Plínio, na edição condensada de Turner, que trata especificamente da consumação de elementos e substâncias formadores da matéria viva do corpo humano, é o de número XXVIII que se intitula Setteth down certain receipts of remedies in physic, drawn from out of man and other bigger creatures (259-91). 
descompromisso com as ciências naturais e humanas correspondia à teologização do universo centrado na cosmovisão religiosa. Se parece ser familiar desde Heródoto o hábito mental europeu de pensar a etnografia de povos distantes de maneira estranha e anômala, ${ }^{8}$ foi entretanto a assimilação de Plínio que na Idade Média favoreceu uma verdadeira fascinação para fabularizar a disformidade alienígena (Whatley 1990, xxii) "at the expense of systematic inquiry into the normal functioning of ordinary, if foreign, societies. ... All through the sixteenth and seventeenth centuries, one finds in travel books a semantic attraction between the term 'America' and the terms 'monste' and 'marvel."'

$\mathrm{O}$ aparente paradoxo antitético, ocorrido na fascinação pelo monstruoso evidentemente encontra o seu corolário na energia e interesse com que os aspectos da natureza ameríndia são visionados pelo descobridor europeu, principalmente aqueles que conceitual e pragmaticamente mais comprometiam a noção de humanidade. E, dentro deles, encontravase em primeiro plano de consideração a antropofagia, motivo proeminente da real ansiedade européia, não só com relação à prática de estratégias a serem utilizadas para a conquista $\mathrm{e}$ dominação mas também com relação aos mecanismos mentais pelos quais a assimilação e a transformação dessa anomalia gentílica seriam feitas nos planos secular, moral e espiritual. Diferentemente da convivência imaginária com o fabulário, agora tratava-se de anomalias humanas de facto testemunhadas, não simplesmente produto de uma tradição folclórica ou literária protegidamente espacializadas ou temporalizadas por teorizações ou sugestoes míticas desnecessitadas da veracidade mimética, herdeiras não só do paganismo clássico, mas ainda da sua refundição na tradição judaico-cristã. Assim é que, de certa maneira, começa a ser confrontada nos primeiros exploradores da realidade americana a validade informativa de antigos livros de viagens (reais ou imaginárias) e cosmográficas laboriosamente concebidos pela tradição, nos quais, dentre os prodígios antropomórficos, encontravam-se, com grande poder de aceitabilidade, a existência terrestre de monstruosas populações caracterizadas desde o ancestral tema pagão ou bíblico do gigantismo até as mais variadas figuraçð̃es de criaturas humanamente aparentadas, tais como, as representações ciclópicas e cinocéfalas, anomalias anatômicas brutalizadas e rudes, mas, às vezes, dotadas de admiráveis funções supernaturais e capazes de surpreendentes gentilezas e bom trato.?

\footnotetext{
${ }^{8}$ A moderna investigação sobre o assunto reconhece que um dos melhores estudos sobre os primeiros tratados etnográficos europeus é o de Margaret Hodgen, Early Anthropology in the Sixteenth and Seventeenth Centuries (1964). Igualmente importante é o estudo de François Hartog que, em Le Mirroir d' Hérodote: Essai sur la représentation de l'autre (1980), trata da influência de Heródoto na maneira de pensar a representação da alteridade alienígena.

${ }^{9}$ Para uma observação detalhada sobre a origem e o impacto causado na mentalidade medieval pela concepção legendária e mitologizada do homem selvagem ver o excelente estudo de Richard Bernheimer, The Wild Man in the Middle Ages: A Study in Art, Sentiment, and Demonology (1970). Ver também os ensaios de Gary B. Nash, Maximillian E. Novak, John G. Burke, Peter L. Thorslev Jr., e especialmente os ensaios de Earl Miner e Hayden White em The Wild Man Within: An Image of Western Thought from Renaissance to Romanticism (1972). Ver ainda Hayden White, "The Forms of Wildness: Archaeology of an Idea," Tropics of Discourse: Essays in Cultural Criticism (1992), ensaio ao qual deve este trabalho a sugestão de idéias básicas.
} 
Se por um lado, o conteúdo narrativo de tais livros de viagens alcançou, na Idade Média e na sua época fronteiriça ao período das descobertas ultramarinas, enorme popularidade informal, por outro, não menos significativa é a importância do grande número de pensadores medievais que abordararn o tema das anomalias universais e dentro delas, direta ou indiretamente, as suas referências e consideraç̃es em relação à natureza humana, num esforço de tratamento analítico e filosófico em consonância com a sabedoria adquirida da Antigüidade e com os valores culturais, morais e religiosos que sustentavam os séculos da medievalidade européia. Uma avaliação, ainda que suscinta, dessa contribuição há que alistar -e para se referir apenas aos seus representantes exponenciais, pois a lista se alongaria com verificações acidentais- nomes representativos a começar por Santo Agostinho (354-430), Santo Isidoro de Sevilha (ca. 560-636) e São Tomás de Aquino (ca. 1225-74), autores aos quais específicas referências serão feitas neste trabalho ao se comentar sobre possíveis influências encontradas na visão narrativa dos primeiros viajantes e cronistas anteriormente citados.

Dentre as considerações mais frequentes desses escritores referentes ao homem selvagem, encontram-se aquelas que dizem respeito à investigação da sua potencial humanidade, referida espiritualmente, e do seu possível estado de racionalidade, aspectos estes ligados à possibilidade da sua conversão e proselitismo cristão. Tais considerações correspondem a elementos de uma formação mental referida não só às premissas do pensamento medieval mas ainda demarcada num rumo encaminhado a renovações do humanismo renascentista, já a despontar-se no período do desenvolvimento das descobertas e experiências ibéricas nas terras do Novo Mundo (Whatley xxiii):

And indeed, even as the news from America was arriving, the humanist enterprise was expanding the dialogue with ancient Greece and Roman beyond such fascinations [i.e., o maravilhoso e portentoso medieval] to include a serious consideration of cultures that were not Christian, but yet could be regarded as admirable for their racionality and civility. Plutarch provided examples of estoic virtue; through the figures of Diogenes the Cynic, or the barbarous Germans of Tacitus, the classical world had reflected upon and criticized its own high civilization; through Ovid's Metamorphoses, an old form of 'soft' primitivism pervaded the Renaissance: the Golden Age, when an innocent human race lived on acorns and honey, trees borne fruits all year around, the earth bore no scar of the plow and the sea no wake of ships, and no one distinguished between 'mine' and 'thine.'

Entretanto, se essa parece ser a configuração do que viria a acontecer para os finais do século XVl, notadamente adentrando-se no XVII —o fenômeno da ficcionalização (alegorização ou literaturalização) do mito medieval do selvagem em Montaigne e Shakespeare-, (White 172) há ainda que se considerar que, embrionariamente, tal tendência já vinha de séculos anteriores:

Bernheimer dates the appearance of the Wild Man as Noble Savage and renewed interest in a presumed lost golden age in Western Europe from the fourteenth century; and he links both developments to the phenomena of cultural crisis. During times of cultural breakdown, he says, men feel the need to return to simpler ways of life, holier times, a need to start the fashioning of humanity over again. ... Bernheimer attributes the flowering during this age ... to the fact that official culture, both secular and religious, had 
become excessively oppressive, while the available forms of sublimation had been preempted by a superannuated and psychotic chivalric nobility.

Sejam quais forem as razões no mundo ibérico - históricas (reconquista política dos territórios ocupados pela civilização muçulmana), morais e religiosas (recristianização), ocorridas predominantemente a partir do século XIV, a verdade é que a imagem benéfica, todavia não excludente do seu contrário, do homem selvagem viria a se radicalizar expurgada dos seus aspectos irremediavelmente condenados à danação eterna, aspectos estes impostos pela mentalidade hebraica, apesar de já temperados em suavidade pela veleidades metafísicas neo-platônicas do cristianismo agostiniano. Posteriormente resgatado pelo racionalismo aristotélico do escolasticismo propugnado pela doutrina tomista, a barbaridade humana entra a compor a noção da razão divina universal a reger em essência a lei natural de toda a existência, inclusive perspectivando a proposta temporal da salvação e cristianização do mundo e das almas, fossem elas barbaramente civilizadas, gentias ou selvagens, premissa essa básica da idéia de um desejável bem comum universalmente, pela vontade e pela razão divina, a ser estendido em relação hegemônica aos soberanos reinos cristãos.

Esse processo de assimilação - primeiramente verificado em relação à tradição pagã e a seguir estendido à realidade das experiências com diferentes culturas encontradas com o alargamento do conhecimento de territórios antes desconhecidos ou simplesmente cogitados - tem sido reconhecido por sua funcionalidade distorsiva, única maneira pela qual a aculturação pôde ser realizada e entendida nos tempos pré-modernos dominados pela dogmática cristã principalmente exposta pela filosofia patrística. Assim é que, as obras de autores clássicos da Antigüidade foram (Hardison 1974, 5) "read universally during the Middle Ages, but - as we know from Fulgentius, Bernard Silvestris, Bercorius and Boccaccio - their work was only admitted to the canon of medieval classics after it had been distorted almost beyond recognition. This process of assimilation was quite conscious."

Seguindo esse procedimento, certos aspectos da concepção clássica -mesmo anômalos, heréticos ou demoníacos - são observados pela filosofia teonômica do cristianismo como fábulas alegóricas pré-figuradoras e reveladoras de verdades cristãs intuídas pelos antigos e consideradas, já no século V (e seguindo as lições agostinianas), como fontes de inspiração divina deixadas para a instrução do estudo da alma humana a se completar com a apreciação da palavra bíblica. Nesse sentido alegórico-exemplar, mesmo o clássico motivo da antropofagia tornava-se facilmente equacionável em função moralística dirigida ao tratamento dos viciosos aspectos da alma humana decaída do conhecimento e aceitação das virtudes divinas e cristãs como, por exemplo (e para se mencionar apenas um dos casos), a freqüente correspondência feita entre a voracidade ciclópica e a arrogância e vaidade do homem. Ainda dentro desse espírito simbólico-figurativo — cujos planos da realidade são dobrados, em virtude da explicação teológica do universo, por uma noção de (Erickson 1976, 27) "all-inclusive awareness of simultaneous realities ... a mutually held world view which found in religious truths the ultimate logic of existence", e de acordo com os ensinamentos da doutrina devocional, a realidade do mundo e as suas variações naturais e humanas revelavam-se como uma alegoria anagógica (espiritual) da onisciente e onipotente vontade e razão divina, do seu enigmático plano da Criação e Redenção 
biblicamente explicado para o entendimento do destino da humanidade e da consumação dos tempos.

O sentido de harmonia cósmica, divinamente originada - não excludente de espécies deformadas e corrompidas pelo pecaminoso afastamento humano das leis divinas-, além de Santo Agostinho, ${ }^{10}$ é concebido nos primórdios do cristianismo medieval pelo teólogo, historiador e enciclopedista Isidoro de Sevilha que nas suas Etimologias o identifica como (Armand 1992, 832) "un mundo de semejanzas y de soterradas pero tenaces y perpetuas relaciones ... donde las marcadas y aislantes diferencias brevemente se entrecruzan, y vacilantes entre la audacia y el dissimulo saborean la ambigüedad de sus pequeñas perverciones". Já durante o século XII, paralela à linha do pensamento humanista de Bernard de Chartres e John de Salisbury, a noção mística da harmonia cósmica reincide particularmente nas obras de Bernard Silvestris (Megacosmus e Microcosmus) e de Alanus de Insulis (De Planctu Naturae e Anticlaudianus) que platonicamente celebram a harmonia e a beleza do mundo visível, apesar das suas marcantes incongruências. Na concepção de Alanus, por exemplo, Deus é o elegante e dourado Arquiteto do Universo, correlacionandose assim a crença da Natureza ser metaforicamente o Livro do Divino Criador, corporificador de conceitos e verdades invisíveis em substâncias, formas e objetos visíveis. " Ecoando a influência do escolasticismo aristotélico de São Tomás de Aquino, a filosofia da harmonia divina do universo virá nos séculos seguintes corresponder à doutrina da lei natural fundamentada originalmente na filosofia estóica de Zeno, Cícero e Sêneca. De acordo com a visão cristã da lei natural, a natureza (todas as suas criaturas e coisas) existem em princípio essencialmente reguladas em virtude da suprema razão divina, adquirindo assim a sua condição de eternidade. Essa filosofia cristã da lei natural, principalmente na Espanha (Castilha) - profundamente marcada pela tradição da mentalidade medieval-e, consequentemente no mundo hispânico do período das descobertas e da ocupação americana, (Stoetzer 1979, 16-60; McIlwain 1953, 326-27) ${ }^{12}$ aplica-se ao pensamento político no sentido de que as verdadeiramente justas leis de governo deveriam refletir e respeitar o princípio da essencialidade divino-racional das coisas, o qual de acordo com a fundamental ética cristã consistia na norma mandatária de promover o bem e evitar o mal.

${ }^{10}$ White aborda esse desígnio divino da harmonia cósmica em sua relação de entendimento com o proselitismo da Igreja cristã propugnado por Santo Agostinho em $A$ Cidade de Deus: "This meant that even the most repugnant of men - barbarian, heathen, pagan or heretic - had to be regarded as objects of Christian proselytization, to be seen as possible converts rather than as enemies or sources of corruption .... Augustine insists that these should not be denied possession of an essential humanity. They must all be conceived to have sprung from 'the one protoplast,' he says ..." (163-64).

"Sobre a influência platônica desses pensadores da chamada Poetria Nova no século XII, ver Brian Stock, Myth and Science in the Twelfth Century: A Study of Bernard Silvestris (1972) e, especialmente, Winthrop Wetherbee, Platonism and Poetry in the Twelfth Century: The Literary Influence of the School of Chartres (1972).

${ }^{12}$ O estudo de Stoetzer, em The Scholastic Roots of the Spanish American Revolution, defende a tese da extrema aderência medievalizante dos princípios da filosofia escolástica aos mecanismos e estruturas adotados pelo governo politico, religioso e moral da conquista e ocupação hispânica das terras americanas, não só no seu período colonial mas também refletindo-se nos processos da sua independência. 
Em linhas gerais (e incorrendo-se no risco das simplificações) este é o complexo quadro ideológico a oferecer-se como hipotexto cultural da visão dos viajantes e cronistas que registraram no século XVI as suas, por vezes coincidentes, variadas impressões sobre a múltipla realidade americana, e dentro dela a surpreendente realidade do nativo, cujo aspecto de maior interesse reflexivo e pragmático, imediatamente constatado, refere-se à sua alarmante e intrigante condição humana caracterizada por detrimentes hábitos e costumes, dos quais o mais insistentemente debatido foram a sua belicosidade e o seu corolário vício antropofágico, sem dúvida alguma, principais oponentes ao plano ideal da exploração e colonização do Novo Mundo, unilateralmente baseadas nos valores e juízos do conquistador europeu. ${ }^{13}$

Pode-se dizer que a primeira versão da antropofagia ameríndia deveu-se a Cristóvão Colombo, principalmente porque tal referência inclui-se no impacto histórico que as descobertas do Almirante causou na era das navegações atlânticas, já expressivas por alturas do século XIV. ${ }^{14}$ No decurso da sua segunda viagem (1493) - no Memorial confiado a Antonio Torres para ser entregue aos Reis Católicos na sua viagem de regresso à Corte em 1494-, Colombo inicia uma distinção entre bons e maus índios, reservando a estes últimos o nome de canibais (Sauer 1992, 31), apesar de na altura não ter ainda visto nenhum deles e não ser-se sabido como chegou precisamente a tal informação. ${ }^{15}$ Colombo propð̃e o envio dos indomáveis canibais à Espanha como escravos, basicamente por duas razões: a

${ }^{13}$ Só mais tarde, já para a fase final da colonização, é que essa visão eurocêntrica (essencialmente arcaica), baseada no complexo cultural do Velho Mundo, torna-se -á, numa fase adiantada do universalismo humanista, assunto de revisão crítica- todavia ineficaz na restauração da verdadeira autoctonia ameríndia, principalmente a partir de Montaigne que, irônica e ceticamente, "desconstrói" a noção canônica do barbarismo fixada no modelo teológico, contra a qual opoe uma noção relativista baseada na antítese entre naturalidade e artificialidade cultural. Para maiores detalhes sobre a exposição filosófica de Montaigne, ver o seu ensaio (publicado originalmente em 1580) "Of Cannibals," na idônea tradução de Cotton em The Essays of Michel Montaigne (1892, 1: 207-21). Da bibliografia sobre o canibal ismo em Montaigne, que já se alonga significativamente, ver especialmente Weinberg, "Montaigne Readings for 'Des Cannibales"' (1968, 264-79); Scaglione, "A Note on Montaigne's 'Des Cannibales' and the Humanist Tradition" (1976, 1: 63-70); Lestringant, "Le cannibalisme des 'Cannibales"' (1982a, 27-40; 1982b, 19-38), "Le Nom de 'Cannibales' de Christophe Colomb à Michel de Montaigne" (1984, 51-74) e Defaux, "Un cannibale en haut de chausses: Montaigne, la différence et la logique de 1' identite" (1982, 919-57).

${ }^{14}$ Descarta-se evidentemente aqui, por razões de comprovação histórica, não só a tradição das místicolegendárias navegaçð̃es clássicas da Antigüidade greco-romana mas também as navegaçð̃es místicoreligiosas do período medieval, das quais - por sua influência mais impressiva na Europa latinizada e crista- destacam-se as obras Visio Tungdali, Navigatio Sancti Brandoni e Purgatorium Sancti Patricci. Sobre o assunto ver a importante súmula de Simoes, A Literatura de Viagens nos Séculos XVI e XVII (1985).

15 Todorov $(1984,30)$ elabora uma explicação linguístico-semiológica para a criação do termo colombino caniba que, dada a sua originalidade, porventura subjetivista, merece ser textualmente citada: "He [Colombo] persists in hearing familiar sounds in their remarks [i.e., dos índios], and in speaking to them as if they must understand him, or in censuring their poor pronuntiation of names or words he supposes he recogruzes. With this distorted understanding, Columbus engaged in some absurd and imaginary dialogues, of which the most sustained example concerns the Grand Khan, the 
primeira porque pensava, para a vantagem de tal provisão, serem as ilhas dos canibais maiores e mais populosas; a segunda —entre idealista e pragmática - refere-se à política de cristianização entrevista pelo Almirante (Colón 1986, 160):

[Y] porque entre las otras islas las de los caníbales son mucho pobladas, parecerá acá que tomar de ellos y de ellas y enviarlos allá a Castilla non sería sino bien, porque quitarse hían una vez de aquella inhumana costumbre que tienen de comer hombres, y allá en Castilla, entendiendo la lengua, muy más presto recibirían el bautismo y farían el provecho de sus ánimas.

O teor de referências como esta - muito contrário à disposição inicial do triunfalismo desejoso de Colombo acerca da simpatia, gentileza, altruísmo e boa conduta dos nativos descritos no Diário da sua primeira viagem - inauguraria o preconceito cultural e religioso sob o qual a qualidade selvagem e pecaminosa dos canibais seria freqüentemente considerada posteriormente. Entretanto, já algumas constantes desse julgamento adjudicativo - motivo de derivadas medidas restritivas no tratamento dos canibais (Sauer 31, 71, 76-77, 161$62)^{16}$ — podem ser inferidas em correspondência a certos substratos dominantes na mentalidade medieval acerca das características tradicionais do arquétipo selvagem, a saber, a visível consideração das suas superiores dotações físicas e bélicas, a sua incapacidade racional em organizarem-se socialmente, da qual a desdotação ou inabilidade lingüística era uma constante freqüentemente observada, e a sua animalidade ou instintividade ligada a hábitos alimentares animalescos e correspondentes a uma certa predisposição libidinal. Evidentemente esses eram os aspectos que maior força oposicional faziam à temeridade não só do sucesso prático da conquista mas também, intimamente a ele ligado, ao seu projeto civilizacional fortemente fundamentado nos (White 157-68) ideais princípios morais e teológicos da tradição européia judaico-cristã. ${ }^{17}$

goal of his voyage. The Indians utter the word Cariba designating the (maneating) inhabitants of the Caribbean islands. Columbus hears Caniba, which is to say, the people of the Khan. But also understands that according to the Indians these people have dog's heads (from the Spanish cane, 'dog') with which, precisely, they eat people. Now this seems to him no more than an invention, and he censures them for it: 'The Admiral believed they were lying and thought their captors must be under the signory of the Grand Khan ..." Para a disseminação dessa nomenclatura e seu entendimento a partir de Colombo, ver Lestringant (1984, 51-74).

${ }^{16}$ Dentre tais medidas restritivas, imediatamente tomadas e constantemente reelaboradas com visível pré-juízo pelo governo da conquista com relação ao controle das ferozes e bárbaras ameaças dos índios canibais, encontram-se as prescrições provisionais estabelecidas para a sua captura e sujeição escravizante, provisðes estas que frequentemente resultaram em arbitrariedades depredativas por parte dos conquistadores espanhóis.

${ }^{17}$ White, no seu citado ensaio, faz uma esclarecedora genealogia do pensamento pagão da Antiguidade clássica acerca da selvageria das espécies anômalas em comparação com a filosofia teonômica da civilização hebraica antiga e a sua derivação no pensamento medieval cristão, mostrando, em linhas gerais, a relativa liberalidade e tolerância greco-romana vis-à-vis a intolerante radicalização hebraica e a prosélita aceitabilidade crista com relação ao tema do homem selvagem. 
Assim é que, ressoantes debates polêmicos do pensamento oficial ocorrem na consideração da nova realidade americana canibalista. Quem seriam teologicamente consideradas a validade das teses agostinianas e tomistas da intenção e vontade divina da Criação vis-à-vis a penetração do mal no universo humano- essas criaturas degeneradas e decaídas na mais pura condição de animalidade? Consequêencias da Queda original, irremediavelmentem a serem praguejadas e condenadas pela transgressão babélica e pósdiluviana, se submetidas à severidade da lei hebraica, ou potencialmente destinadas à salvação espiritual, se consideradas sob a condição do pecado original e, portanto, conseqüentemente redimíveis através do espírito universalista consolidado na prática proselista da caritas instituída pela doutrina da graça divina messianicamente difundida pela igreja cristã? No âmago de considerações como essas sobre a possível humanidade indígena - aqui sinônimo da presença da alma $^{18}$-, as diferentes visões relatadas pelos cronistas e viajantes acerca dos índios canibais curiosamente refletem considerações microssemanticamente ligadas a arcaicos motivos bíblicos, tais como, o gigantismo e a superioridade física e titanicamente bélica, a confusão lingüística babélica e um mínimo remanescente de humanidade edênica ainda preservada entre os selvagens como, por exemplo, a sua nudez inocentemente exposta e isenta da vergonha moral do sexo estabelecida pela metáfora indumentária do pecado original. ${ }^{19}$

A partir das referências de Colombo, cresce o interesse pelos selvagens das ilhas caribenhas do sul, cuja presença canibalista era também suspeitada em terra firme a elas contígua, na então chamada região dos párias. Se por um lado a figura incivilizada do primitivismo selvagem era motivo de inconformadas considerações no plano moral e teológico, por outro, esse mesmo primitivismo, associado a idéias remanescentes da cultura clássica - cujo paganismo fora cristianizado para além do seu reconhecimento original, oferece-se como respaldo positivo para um incipiente retorno à mitológica idéia da Idade Dourada das arcaicas arcádias, numa fase em que a mística obsessão colombina da existencia do Paraíso Terrenal em terras americanas se apresenta mais secularizada, posteriormente, no decurso das descobertas. ${ }^{20}$ Com a crescente difusão da imprensa, coeva com o espírito

\footnotetext{
${ }^{18}$ Para a consideração da ancestralidade bíblico-genealógica dos nativos americanos em referência à prole adâmica, ão titanismo pré-diluviano, à geração de Babel e aos descendentes corruptos de Noé, ver a introdução de Whatley e o ensaio de White anteriormente citados.

${ }^{19}$ A questão da possibilidade da alma dos selvagens, bastante discutida desde o neo-platonismo cristão de Santo Agostinho até o aristotelismo escolástico de São Tomás de Aquino, parece ter recebido uma solução definitiva - ainda que discutida oficialmente pela sanção eclesiástica, mas nem sempre seguida na prática pelos agentes das conquistas - a partir da Bula de Paulo III, a Sublimus Deus (1537) - apesar de imprecisa em seus princípios categóricos— já numa fase adiantada da ocupação das terras do Novo Mundo, marcada por celeradas arbitrariedades na dominação e aplicação do Requerimiento possivelmente datado de 1513. Para a discussão dos termos e embasamento filosófico da jurisdição religiosa e secular acerca da humanidade da alma indígena, ver Lewis Hanke (1959) e especialmente o seu ensaio "The Theological Significance of the Discovery of America" (1976, 363-90).

${ }^{20}$ Para uma visão ampliada das fontes e comentários sobre o mito da Idade Dourada ressuscitado pela ação do humanismo renascentista, ver Harry Levin (1972). Especialmente sobre a idéia do primitivismo associado a motivos da Antigüidade clássica ver Arthur Lovejoy e George Boas (1965). Ver ainda sobre o assunto o relativamente pouco citado, mas fundamental estudo comparatista de Sérgio Buarque de Holanda (1969).
} 
dos descobrimentos e com uma verdadeira fome de informaçð̃es (Quinn 1976, 635-58), começa uma simbiose funcional entre imagem e divulgação da multiforme natureza americana, tornando se bastante complexa a diferenciação entre realidade factual e impressão, fato que, associado ao ainda tradicional gosto pela herança da literatura imaginativa e fabulária medieval —-de permeio com a já incipiente ressurreição do cabedal legendário clássico (Gerbi 60) ${ }^{21}$-_, inicia a lenta gestação especulativa e figurativa da América, para a qual a crítica contemporânea tem re-utilizado o termo invenção. ${ }^{22}$

Contemporâneas ao relato de Colombo sobre a natureza ameríndia e a sua referência ao canibalismo encontram-se as cartas de Alvarez Chanca e Michele da Cuneo, ambos acompanhantes do Almirante em sua segunda viagem. ${ }^{23}$ Diferentemente de Colombo cujas observações, de maneira geral, praticamente se isolam porque entremeadas de considerações várias-, Alvarez Chanca, e principalmente Michele da Cuneo, mostram-se mais realistas, apesar do tom de constante deslumbre do primeiro e da atitude sensacionalista, entre jocosa e jovial, do segundo. Entretanto, no que concerne à descrição dos nativos e canibais, deve-se a Cuneo a tentativa de explicações mais sistemáticas. Comuns a ambos é a atitude de completa disforia e desidealização em referência à figura do índio, o contrário do que mais tarde ocorreria com as idealizações - fruto do humanismo cristão, uma mistura entre idade dourada e edenismo- de cronistas voltados a interesses políticos e pragmáticos na exploração dos proventos materiais e espirituais da América. Ao que parece, o doutor Chanca, apesar do seu espírito científico, e Cuneo refletem em suas descriçóes e comentários sobre a natureza ameríndia uma postura de visível etnocentrismo europeu; uma atitude de superioridade na observação do estado de bestialidade humana encontrada. Ambos referem

${ }^{21}$ Parece que nem toda crítica moderna é unânime - a exemplo de Gerbi que se inclina para os saldos positivos do espírito humanista nas descobertas - em avaliar a contribuição dessa vertente do Renascimento, principalmente em relação à depicção idealizada e preformada dos nativos, cuja figura irrealiza-se e abstratiza-se ao ser (Whatley xxiii) "portrayed [no que veio a ser a primeira sistemática e compreensiva obra sobre a América —as Décadas de Pedro Mártir] in the forms and poses of the gods of classical antiquity."

${ }^{22} \mathrm{O}$ tema da invenção alegórica ou ficcional da América já se faz notar desde as primeiras histórias dos descobrimentos hispânicos, como parece atestar a Historia de la invención de las Indias de Hernán Perez de Oliva, obra do século XVI cujo manuscrito, desaparecido e recentemente resgatado, foi editado por José Juan Arrom em 1965. "El primero fue Giuliano Dati que utilizó el término [invención] en 1493" (Armand 835). Nessa esteira, que já se alonga significativamente, há que citar-se a obra fundamental (1961) - controversa - de Edmundo O'Gorman, originalmente publicada em espanhol em 1958. Mais recentemente, cita-se o livro (1982) de Enrique Pupo-Walker que estuda, com ampla base documental e bibliográfica, o substrato ficcional da historiografia hispanoamericana desde as suas origens até o século passado.

${ }^{23} \mathrm{O}$ doutor Chanca, apesar de relativamente desconhecido e pouco tratado historicamente, referenciase pela carta que escreveu de Espanhola (fins de 1493, princípios de 1494?) ao (Gerbi 23) "cathedral chapter [de Sevilha; documento importante não só devido à] ... rarity of other authentic accounts of the second voyage [de Colombo, mas também como estilo de um] ... shrewd, lively and accurated observer ..." Quanto a Michele da Cuneo (nativo de Savona), mais referido do que Chanca - talvez porque (Gerbi 31) "unstintingly reveals the whole living world [o que observou na América] and seeks to summarize its salient characteristics"-, a sua contribuição consta da carta (15-18 de outubro de 1495) que escreveu a Gerolamo Annari. 
- curiosamente antes dos fundamentos aristotélicos que escolasticamente motivariam a severidade jurídica aplicada à noção da natural condição de subserviência infligida ao selvagem irracional e animalizado — aos seus (Gerbi 33) "filthy habits," sendo Michele da Cuneo quem completa esse retrato degradante ao comentar, com riqueza de escabrosos detalhes, sobre as bestiais práticas sexuais dos nativos. Entretanto, adianta Cuneo certas importantes informações - porque posteriormente freqüentes motivos de consideraçãoacerca do canibalismo. Registra, por exemplo, (Gerbi 34) uma curiosa explicação para a prática canibalista ligada à sodomia, dizendo que os índios de virilidade amaneirada haviam contraído essa praga viciosa dos canibais selvagens que ao subjugá-los, antes de devorálos, forçavam-nos à sodomia como marca de humilhação, causando assim o desenvolvimento e o gosto desse hábito. ${ }^{24} \mathrm{Em}$ suma, as cartas de Chanca e Cuneo - pelo seu descompromisso com a responsabilidade oficíal de relatores - refletem, se não a faceta de uma desinteressada objetividade própria do Renascimento, ainda não temperado com idealizações abstratas, porventura, o aspecto empirista daquela visão medieval, onde o estranho e o incomum penetram na realidade tão naturalmente, consequência talvez ambivalente de uma tradicional e familiar convivência com a naturalidade do fantástico e do imaginário. ${ }^{25}$

Continuando o gênero epistolográfico relativo às descobertas mundonovistas, encontrase a figura de Amerigo Vespucci (o verdadeiro Vespúcio), florentino responsável por três viagens às terras americanas, a primeira a serviço do rei da Espanha e as duas seguintes contratadas pelo rei de Portugal. ${ }^{26}$ Diferentemente de Colombo e mais semelhante a Chanca e Cuneo, a atitude de Vespúcio indica ser mais (Gerbi 35-36) "realist because despite his merchant origins he is always motivated first and foremost by scientific curiosity .... [Aspecto que o levou a ser considerado como] brought up in the most cultivated society of the Renaissance and endowed with a healthy dose of ironic skepticism". ${ }^{27}$ Se é verdade que o interesse do piloto florentino é principalmente cosmográfico e cartográfico, não menos verdade parece ser a sua atenção dedicada à natureza observada, e dentro dela, aos nativos. Com maior seriedade do que Chanca e isento da maliciosa concuspicência de

\footnotetext{
${ }^{24}$ Curioso é notar, em Cuneo, o fato dessa observação apresentar-se assim detalhada em referência à segunda viagem em que fez com Colombo, quando (Sauer 31) o próprio Almirante parece não ter tido nessa época experiências mais concretas com os índios canibais.

${ }^{25}$ Para a tese dessa característica cultural da mentalidade medieval alheia à curiosidade universal dos humanistas, portadora de uma "resignação ao real e ao imediato, essa cautelosa e pedestre razão," referida como traço ibérico principalmente lusitano, ver Holanda (103).

${ }^{26} \mathrm{O}$ autêntico legado do missivista consta de três cartas endereçadas a Lorenzo di Pier Francesco de' Medici, a primeira datada de Sevilha em 18 de julho de 1500, a segunda de Cabo Verde em 4 de julho de 1501 e a terceira de Lisboa em 1502.

${ }^{27}$ Essas características que o próprio Vespúcio a si reconhece - a racionalidade da experiência direta com o objeto do conhecimento, tirante o seu confessado ceticismo tomista-, se parecem constituir, por um lado, o aspecto pragmático do humanismo, por outro não deixam também de supor aquela faceta empírica da medievalidade, principalmente se se considerar o período fronteiriço entre essas duas tendências no qual viveu Vespúcio. O próprio Gerbi (39-40), após citar estudos prévios sobre as características renascentistas em Vespúcio, tende para a aproximação do seu humanismo em fusão respeitante aos ensinamentos da patrística bíblica.
} 
Cuneo, Vespúcio (Gerbi 38) observa a naturalidade moral da completa nudez dos indígenas e o hábito cultural de se depilarem, traçando deles um retrato visivelmente mais positivo em relação à etnografia tradicionalmente imaginada para os povos alienígenas: "[T]hey are not deformed or monstruous, as Europeans imagined the 'antipodeans': they are well built and well proportioned, agile, numerous, and long-lived [não fracos e de curta vida, como notara Cuneo]. They are undubitably men, and Vespucci becomes so unterested in them that he tends to skimp the rest of the description or treat it almost as mere background and setting for his cannibals."

Vespúcio - (Bandini 1745, 80) que parece ter sido o primeiro dos exploradores a ter contacto mais direto com os canibais americanos- deixou observações realmente inquisitivas sobre a organização dos selvagens, tais como, a ausência de leis e de religião firmemente estabelecidas, o desconhecimento da imortalidade da alma e o sistema da comunalidade dos bens. Apesar da poligamia, percebeu entre os nativos uma certa constituição marital baseada principalmente no sentimento do ciúme. Entretanto, o que sem dúvida alguma constitui a mais importante observação de Vespúcio é a sua descrição, com incrível objetividade, da relação entre a selvagem belicosidade guerreira e o canibalismo, não deixando entretanto de horrorizar-se não só com os seus sangrentos massacres mas também - e maiormente - com a elaborada prática culinária dos canibais - a técnica da defumação para o consumo da carne humana-, a qual o narrador não relaciona, apesar do seu possível contacto com textos clássicos do Humanismo (!), com a hedonística antropofagia polifêmica (Eurípedes), nem à sofisticada crueldade canibalista de Sêneca, anteriorrnente comentadas. Entretanto, percebe -e este parece ser já um traço da mentalidade renascentista - que, diferentemente das razões que motivam as guerras do mundo civilizado, as guerras canibalistas dos prirnitivos índios americanos faziam parte de um ancestral costume emulador do motivo da vingança, espécie de princípio ético fundamentado em valores naturais e heróicos que posteriorrnente constituiriam o apanágio da defesa idealizada e utópica do Noble Savage em sucessivas gerações européias.

Diferentemente do comportamento de equalitarismo cristão e assimilacionista de Colombo - substrato de uma mentalidade medieval sustentada pelo espírito teológico das Cruzadas-, Vespúcio nota entre os nativos uma variedade independente de idiomas, não (Todorov 1984, 22-23, 42-44, 46-47) uma divergência lingüística que o Almirante imbuído na concepção fonocêntrica da superioridade cultural européia- havia concebido

\footnotetext{
${ }^{28}$ Parece que a debatida teoria aristotélica da inospitabilidade e impossibilidade de vida em terras sub-equinociais, apesar de já ter sido contestada por Santo Agostinho, era ainda assunto controverso na era das descobertas. Holanda (284) analisa o anti-antípoda topos da "temperança" que constante de legendárias descriçð̃es medievais acerca do edenismo terrenal é transferido para a geografia das terras equinociais, motivo que ajudou a "desfazer, não propriamente qualquer dúvida acaso existente sôbre a formosura de sítios atravessados pela equinocial, mas aquêle engano em que muitos se achavam acêrca do seu clima. Desenvolver êsse parecer favorável à salubridade, amenidade, gentileza e temperança de lugares tidos por outros como inóspitos e doentios, é o objetivo essencial de um escrito que Richard Hakluyt, ainda em 1599, não parecia julgar irrelevante, tanto que o fez imprimir." Para uma abundante fonte de citações antigas e modernas sobre a discussão da unsalubridade e inabitabilidade das zonas tórridas, ver Atkinson (1935, 255-91).
} 
como corrupção (babélica?) do espanhol da messiânica Castilha cristianizadora do mundo, inclusive com suposição profética respaldada pela revelação bíblica. Evidentemente, o interesse de Vespúcio além de não ser a prática lucrativa do comércio não é seguramente o de um missionário.

Dentre os relatos escritos a partir de experiências diretas com as terras americanas, ainda as duas primeiras décadas de Quinhentos registram duas significativas contribuições não mais em forma epistolar, mas de caráter mais sistemático e abrangente. Tratam-se do tratado Suma de Geographía - o primeiro livro impresso em espanhol (1519) referente à América- de Martín Fernández de Enciso e o diário de navegação de Francescantonio Pigafetta de Vicenza, publicado inicialmente em francês em 1525, incluído (parcialmente) na coletânea enciclopedística dos relatos dos descobrimentos de Ramusio de 1550-1556 e ficando, finalmente, conhecido na tradução inglesa pelo título First Voyage Around the Terracqueous Globe ou Around the World. ${ }^{29} \mathrm{O}$ relato de Pigafetta, assim como o tratado de Enciso - dado o interesse do primeiro nos arquipélagos asiáticos (as ilhas das especiarias chamadas Moluccas), e no caso do segundo, devido à vastidão do assunto de que pretendeu tratar (não só as Índias Ocidentais mas o mundo inteiro)-, abordam o problema da natureza americana num limitado espaço de tratamento. Em Pigafetta, descontando-se as suas rápidas observações de valor objetivo, contribui para a desvirtualização da sua utilidade documental o tradicional material legendário e fabuloso que o autor introduz no seu relato acerca das terras americanas. No caso de Enciso - dado o caráter quase exclusivo da intenção do seu tratado em servir como guia prático para pilotos e navegadores e ainda devido à sua encomiástica defesa da tese da hegemonia mundial político-dinástica de Carlos $\mathrm{V}$-, as descrições das Índias Ocidentais tendem a ser sobretudo comprometidas com interesses imperialistas. $^{30}$

Sendo essas as circunstâncias escriturais a que os dois autores conscientemente se submetem, nota-se que as suas descrições dos ameríndios tendem a se sujeitarem a um certo finalismo de interesses não muito diferente em seus motivos básicos da faceta pragmática de Colombo, ainda que mais visivelmente secularizado. Entretanto, de maneira geral, ambos demonstram uma receptividade quase ingênua para com os indígenas; uma certa simpatia ou interesse humano, todavia limitados. Enciso refere-se aos nativos como (Gerbi 83) "good people, although naked," observando neles uma certa integridade de procedimento e sabedoria natural, dando informações adicionais sobre os seus costumes canibalistas como, por exemplo, o hábito de "fatten up their prisoners before eating them ... [dizendo que] 'the most tasty morsel, so they say, is the fingers, and the lean of the man' loins." "31 Tudo isso Enciso registra com uma certa incredulidade, se se levar em

\footnotetext{
${ }^{29}$ Sobre o problema das vicissitudes por que passou a publicação de Pigafetta, a sua difusão no conhecimento da época, a identidade do autor e os resultados exploratórios da expedição do português Magalhaes, a serviço da Coroa espanhola, na qual participou Pigafetta, ver Gerbi (100-03).

${ }^{30}$ Para detalhes desse aspecto político em Enciso - inclusive o seu envolvimento na instituição das bases teológicas e jurídicas do Requerimiento (que o autor advoga ser de sua autoria), ver Gerbi (7883).

${ }^{31}$ As citações de Enciso são extraídas de Gerbi pelas mesmas razões de raridade que o autor nota a respeito das edições da Suma de Geographía. Sobre o assunto, ver Gerbi (77 n.2).
} 
consideração (Gerbi 85) os restritivos remarques que faz acerca do fabuloso medieval sobre as terras estranhas, ao qual se refere dubitativamente por não ser do seu conhecimento empírico.

Tal preferência de Enciso pelo empirismo sobre a mera informação testemunhal alheia parece não corresponder ao manifesto gosto de Pigafetta pelo exótico, com as suas sensacionais descrições de fenômenos encontrados, muitas vezes não se preocupando em marcar claramente se tais fenômenos são do seu próprio testemunho ou de outrem, mas sim curiosamente pede - na hipótese do segundo caso- que seus leitores acreditem realmente no simples fato de ele ter recebido a informação narrada. Neste caso (Manfroni $1929,253,258)$ relembra não só antigas e anônimas lendas medievais mas também (e mais referencialmente) derivações de Plínio e Mandeville. Entretanto, diferente da quase incredulidade de Enciso, Pigafetta, apesar de tendente a fantasias, demonstra uma firme convicção acerca de certas características que supõe evidentes nas suas observaçð̃es sobre a natureza dos nativos. Não duvidando da sua humanidade - à semelhança de Vespúcio no seu esforço de entender o indígena e justificá-lo racionalizando os seus costumes-, Pigafetta refere-se, ainda diferentemente de Enciso - que discorre sobre verbosos exempla de natureza teológica fornecidos pelos ameríndios, apesar de claramente considerá-los idólatras-, ao fato de que se eles não podem ser considerados cristãos, pelo menos neles não descobre nenhum traço de idolatria, assemelhando-se ainda aqui às considerações de Vespúcio. Dessa maneira, o cronista de Magalhães, assim como antes fizera o piloto florentino, demonstra um real interesse com relação à singularidade dos costumes nativos, adicionando importantes informaçð̌es acerca da autoctonia do fenômeno canibalista como, por exemplo - além da técnica da defumação da carne das vítimas (Vespúcio), do costume de engordar os prisioneiros antes do sacrifício (Enciso), do motivo heróico do telúrico espírito de vendetta das guerras canibalistas (também referido por Vespúcio e repetido por Pigafetta)-, a explicação que recebe, talvez pela primeira vez na história do canibalismo americano, sobre a origem do próprio costume, já com informações acerca da sua natureza ritualística. ${ }^{32}$ Dada a interessante originalidade da referência (Pigafetta 1874, 44-45), a passagem, apesar de extensa, merece ser, entretanto, citada na íntegra:

Now this custom arose as follows: an old woman of this place of Verzim had an only son, who was killed by his enemies, and some days afterwards, the friends of this woman captured one of the said enemies who had put her son to death, and brought him to where she was. Immediately the said old woman, seeing the man who was captured, and recollecting the death of her child, rushed upon him like a mad dog, and bit him on the shoulder. However, this man who had been taken prisoner found means to run away, and told how they had wished to eat him, showing the bite which the said old woman had

\footnotetext{
${ }^{32}$ Hans Staden (1974, 134-76), no livro referente à sua segunda viagem ao Brasil (1550-1555) -ao que parece fidedigno no relato, dada a sua experiência pessoal (facilmente comprovada na época) como prisioneiro a ser canabalizado pelos tupinambás-, relata, com surpreendente semelhança às observaçðes de Pigafetta, não só o motivo porque os canibais devoravam o inimigo aprisionado mas também o sistema e o sentido ritualístico dado ao consumo da carne defumada. O relato de Staden foi originalmente publicado com o título (abreviado) de Wahrhaftige Historie (Marburg, 1557).
} 
made in his shoulder. ${ }^{33}$ After that those who were caught on one side or the other were eaten. Through that arouse this custom in this place of eating the enemies of each other. But they do not eat up the whole body of the man whom they take prisoner; they eat him bit by bit and for fear that he should be spoiled, they cut him up into pieces, which they set to dry in the chimney, and every day they cut a small piece, and eat it with their ordinary victuals in memory or their enemies. I was assured that this custom was true by a pilot, named John Carvagio, who was in our company, and had remained four years in this place ...

Assim é que, pouco a pouco, paripasso com a revelação da natureza, as imagens do nativo se vão definindo e sendo usadas, ora com maior aproximação realista, ora em direção à predominante figuralidade característica dos relatos posteriores ao século XVI. Dentre os responsáveis por esta tendência elaborativa, já no século XVI, encontram-se as figuras de cronistas compiladores de informações oriundas de segunda mão como, por exemplo, Nicoló Scillacio, o pseudo -Amerigo Vespucci e Pietro Martire d'Anghiera. Embora a contribuição desses escritores não se limite ao escopo deste ensaio - que procura registrar sobretudo a observação direta em referência à realidade americana-, alguns comentários gerais merecem ser feitos com relação à difusão e assimilação dessa realidade nesses escritores que nunca viajaram à América, mas que sobre ela escreveram com a curiosidade e a inferição próprias de quem ingênua, sensacionalística ou oficialmente se encarregou desse mister. O primeiro deles, talvez mais por importância cronológica do que pela validade interna da sua escrita, foi o doutor siciliano Nicoló Scillacio que na sua epístola De insulis meridiani atque Indici maris nuper inventis, consciente da sua incapacidade de testemunho empírico (Gerbi 27) "confines himself to repetition and dissemination, contributing nothing of his own". ${ }^{34}$ Apesar dos seus grosseiros erros históricos e das suas assistemáticas e pouco precisas observações, as impressoes de Scillacio servem mais para retraçar o estado de deslumbre e admiração triunfalista com a qual a novidade americana desde Colombo atingiu a disposição mental européia da época. Com relação aos nativos, Scillacio segue a já disseminada noção colombina da divisão entre índios bons e ferozes canibais que (Gerbi 29-30) "wage unceasing war on the Indians, who are meek and fearful, for culinary purposes ... [e] they have the cruel habit of fattening up the captured children like capons, after castrating them ... It will be no easy task to induce them to accept our laws and customs ..."'35

\footnotetext{
${ }^{33}$ Interessante é notar aqui a coincidência da ancestralidade do princípio feminino na antropofagia primordialmente registrada em Hesíodo, e inclusive (Mariotti 1977, 13-17) referida teoricamente por Freud e Lévi-Strauss ao associarem o canibalismo à economia libidinal-alimentar e ao incesto. Para a minuciosa descrição da importante atuação das índias tubinambás no canibalismo brasilíndio, ver Staden (91-93, 175, 178-79).

${ }^{34}$ A epístola de Scillacio, datada de 13 de dezembro de 1494, fora endereçada a Ludovico il Moro.

${ }^{35} \mathrm{O}$ conhecimento da prática canibalista vai, pouco a pouco, se anatomizando com detalhes negativamente funcionais para a aceitação européia. Como em Cuneo, aqui e já pela segunda vez, o motivo da castração se faz presente e torna-se-ia assunto de referência em futuros relatos sobre os ameríndios. Interessante, entretanto, na comparação desse motivo, é o fato de que Staden o omite completamente na sua Wahrhaftige Historie. Por outro lado —e já saldo positivo na configuração
} 
Semelhantemente a Scillacio - pelas suas aduções comentaristas de empréstimo, mas com maior grau de elaboração inventiva, entretanto falsificadora e plagiária - são as duas obras deixadas pelo considerado pseudo-Vespúcio, o tratado Mundus Novus (1504) e a carta a Pier Soderini conhecida como Quatuor Navigationes (1504), as quais (Gerbi 45) "were drafted by some unknown and not very talented scholar in the early sixteenth on the basis of the Florentine's [i.e., o verdadeiro Américo Vespúcio] few and sober original letters, and rushed into print to exploit the momentary thirst for information on the New World and the eternal hunger for tales of marvels and fantasy." Apesar de denunciado ao que parece não só por gerações dos séculos posteriores mas ainda na atualidade — pelo seu estilo de rude, picante e grotesco sensacionalismo sem dúvida exagerador dos hábitos e costumes dos selvagens, os relatos do pseudo-Vespúcio contribuem de certa maneira para a apreciação da psicologia social ao nível da recepção cultural da época marcada pelo gosto consumista e inventivo da susceptível e motivacionável mentalidade híbrida popular pré-renascentista. Se, entretanto, relatos como os do pseudo-Vespúcio foram olhados com severa reserva pela historiografia oficial, por outro lado, além da preferência popular, (Gerbi 46) despertaram um certo interesse e admiração por pensadores mais liberais da nova estética humanista.

Talvez o que mais tenha atraído no pseudo-Vespúcio tenha sido o seu tom de legendarismo entusiástico pela América, no qual a sua característica de gigantismo (motivo da ancestralidade bíblica em simbiose com o paganismo) fica bem marcada como traço identificador da diferença do Novo Mundo. Entretanto, com relação ao retrato composto para os índios canibais, o pseudo-Vespúcio pouco ou quase nada adiciona ao anteriormente feito pelo seu homônimo, a não ser certas conotações provavelmente herdadas da tradição clássica e concernentes com a preocupação evangelizadora, das quais a mais reforçada era a noção - já desejada pelo adventício e prospectivo plano cristianizador de Colombo- da ausência de qualquer idolatria. Embora sendo os canibais os piores descrentes do mundo, mesmo assim tal disposição podia ser considerada positiva para a impressão incontroversa dos modelos da crença cristã, sem a necessidade de maiores esforços na luta ideológica contra gentílicos ou pagãos ritos bárbaros. ${ }^{36}$

Finalmente, mas não em grau de importância na lista dos escritores de experiência indireta no relato das novidades do Novo Mundo, menciona-se o nome do milanês Pietro Martire d' Anghiera, cujas Decadas de Orbe Novo ${ }^{37}$ possuem um caráter enciclopedístico, abarcando informações de gêneros diversos - desde cartas, panfletos, relatos e impressões-

dos selvagens-, Scillacio, semelhantemente a Vespúcio, nota o seu sistema da comunalidade de bens, imagem ovidiana que seria obsessivamente repetida nos séculos seguintes na ficção alegórica do Noble Savage.

${ }^{36}$ Todavia esse aspecto político do pensamento evangélico parece não ser considerado nas inferências que Gerbi faz acerca do pseudo-Vespúcio na sua consideração do estado de espiritualidade dos nativos americanos.

37 "The first three Decades were published together, with the author permission, in 1516 .... All eight Decades were published in 1530 ..." sendo, entretanto, a obra do autor, prévia ou posteriormente a esta data, reimpressa e traduzida (parcialmente ou na íntegra) em vários idiomas e alcançando grande popularidade (Gerbi 50-53). 
constantemente revistas por adições, comentários e freqüentes revisoes do autor. O seu estilo latinizante e classicizante leva-o a ser considerado (Gerbi 51) "a true son of the Renaissance and a good man of letters. He has the sense of measure, of what is elegant and fitting, a taste for the pleasing and agreeable rather than the enormous and fearsome." Entretanto, os termos dessa identificação renascentista parecem não poder excluir aspectos da obra de Pedro Mártir que traduzem uma visível marca medieval, tais como, o gosto enciclopedístico e o afã por detalhes, ainda que seja verdade que tal espírito colecionador tenha já evoluído no autor em direção a um interesse universalista mais comedido e refinado, para além da indiscricionária estética medieval que se indefine, numa das suas facetas características, pelo hibridismo das suas incongruências portentosas e emossêmicas.

Talvez o que tenha sobretudo distinguido o lado humanista de Pedro Mártir seja o descortíneo objetivo com o qual aprecia a vida natural dos selvagens, sem os vícios pecuniários e jurídicos da civilização. O único —e paradoxal— senão desse primitivismo dourado, segundo Mártir, era a ausência do cristianismo e a manifesta belicosidade guerreira dos índios motivada pela ambição e posse territorial, ponto de vista que o autor não partilha com Vespúcio. ${ }^{38}$ Apesar da clara simpatia e boa vontade manifestadas com relação aos nativos, no que se refere às suas crueldades e dentro delas o canibalismo —e diferentemente das obsessiva generosidade pró-indigenista de Las Casas e das ferozes invectivas de Sepúlveda contra o ledo engano europeu na idealização dourada do selvagem americano ${ }^{39}$ Pedro Mártir procura manter-se politicamente imparcial.

Se Mártir, assim como Oviedo, representam a ampliação dos horizontes medievais do Velho Mundo- (Gerbi 60) "expand man's understanding of the natural kingdoms, foster new sciences and fresh researches and, within the compass of their intellectual effort, also include the native ... raising him up to human dignity even while most savagely denouncing his vices and limitations"-, ainda assim as suas alegorizações humanistas representam -como havia anteriormente acontecido com a inserção do legendário e fabuloso medieval - uma irrevocável alienação eufórica da América a caminho das grandes utopias iniciadas por More e já plenamente desenvolvidas no século XVIII. Na verdade, toda essa literatura tendente a idealismos "progressistas." apesar da sua aceitação oficial, religiosa e secular, pouco ou quase nada contribuiu para determinar (Stoetzer 16-45) o processo colonialista americano intrinsecamente fundamentado em padroes arcaicos, cuja

\footnotetext{
${ }^{38}$ Gerbi $(54$ ns.13, 14), comentando sobre a inquestionável presença (suposta por Pedro Mártir) da "praga" bélica mesmo no seio da Idade Dourada, conclui que o autor manifesta uma verdadeira "nostalgia for primitivism, quite without malice toward either Old and New World." Entretanto, parece ser difícil conciliar esse comentário com a observação que Gerbi (55 n.17) atribui a Pedro Mártir acerca do "peace-loving communism" dos selvagens americanos. Talvez a contradição resida no fato de que os juízos de Mártir expressam não uma notação renascentista per se, mas sobretudo -e ironicamente - o tipo de humanismo que transposto para o plano da conquista muitas vezes caracterizou-se por revelar erros morais dos selvagens a fim de compensatoriamente justificar procedimentos semelhantes mantidos pela ideologia dos conquistadores.

${ }^{39} \mathrm{Já}$ em 1547, esse grande contendor escolástico das teses de Las Casas verificara que na realidade -e talvez movido pela pragmática política da colonização- (Sepúlveda 1941, 104-06), era absolutamente desumano o componente selvagem do canibalismo.
} 
práxis política encontra as suas justificativas ideológicas em função de uma metafísica espiritual que correspondia a noção temporal do Império espanhol a dogmas e princípios teológicos escolasticamente versados.

O próprio Gerbi (60) que tão enfaticamente parece referir-se à quase unânime simpatia do colonizador para com a natureza ameríndia, apesar de declarar - parecendo generalizar e contrariamente a Stoetzer - que "[t]he investigation of the American nature [e aqui referindo-se especialmente a Pedro Mártir e Oviedo], including the native is still wholly within the spirit of humanism, striving after a better knowledge of the world ... [e que] It accompanies (and sometimes serves to support or bolster up) the exploits of the discoveries and conquistadors." ainda assim não deixa de ponderar que devido à proposta comercial e política

[t]hose great deeds are in fact a repetition and a continuation of what had always been done in Europe; they follow on from the trend of events in the closing centuries of the Middle Ages and are aimed, more or less consciously, at balancing or blunting revolutionary developments in the Old World, the advance of Islam and the resulting blocking of the path to the East, or the Lutheran reform robbing the church of half of Europe.

A historiografia dos primeiros escritos sobre a América parece portanto revelar uma clara distinção (extensiva à visão do nativo) entre aqueles viajantes que escreveram com a intenção (ou encargo) oficial de conquista e colonização e aqueles que escreveram simplesmente com o espírito de investigação e conhecimento individual da novidade. ${ }^{40}$ Dentro desse esquema classificatório (todavia sem radicalismo redutivo), uma tipologia da mentalidade dos primeiros encontros com a realidade americana e a dos nativos principalmente com a sua controversa natureza canibalista - parece poder ser tentada. De um lado situar-se-iam os partidários da visão colombina- Chanca, Cuneo, Scillacio e Enciso - que, de certo modo, configuram os indígenas ainda sob a sugestão dos motivos do mito do homem selvagem radicados tradicionalmente na mentalidade medieval. Neste sentido, o selvagem americano torna-se representado, ao mesmo tempo e ambiguamente, como portador de distintas qualidades naturais meritórias, mas decaídos no decurso da história humana teologicamente revelada. Assemelha-se, por isso mesmo, ao illo tempore mítico da humanidade recém-corrompida pelo período pós-edênico e pós-diluviano, com o predomínio de apetites instintivos e pré-racionais e, dentro deles, a voluptuosidade alimentar e carnal do canibalismo que corresponde arquetipicamente a consumação da energia vital ao princípio tanatológico. Daí o pavoroso temor, condenação e propósito reformista (ideal e pragmático, isto é, cristão e supressor) que determinam a visão —entre aflita, simpatizante e objetificante- dos conquistadores movidos pela intenção de domínio da terra e do homem. Característico dessa visão é o seu finalismo referencial alocêntrico, muito diferente da objetividade desinteressada que identifica um dos aspectos do humanismo

\footnotetext{
40 Villoro $(1950,15-88)$ considera o livre espírito de investigação da novidade mundonovista de certos viajantes europeus agudamente contrastivo com a intenção política e missionária dos conquistadores responsáveis pela tragédia civilizacional infligida aos nativos. Sobre o assunto, ver também Morse (1954, 71-93).
} 
antes das suas simbólicas derivações utópicas e alegóricas e do seu esteticismo abstrato e universalista. De outro lado, talvez sejam a incipiente atitude renascentista do verdadeiro Vespúcio (e de certa maneira do pseudo-Vespúcio), o humanismo ilustrativamente assimilado de Pedro Mártir, e certos aspectos do interesse humano de Pigafetta os responsáveis pela informação e investigação da excepcional, mas procuradamente inteligível realidade do Novo Mundo, para além das suas desconfortantes disparidades. Todavia, ainda por demorados séculos, a apreciação da América nativa terá que se submeter irremediavelmente ao legado arcaico do tradicional pensamento oficial do apropriador conhecimento europeu.

\section{BibLIOGRAFIA}

Armand, Octavio. América como mundus minimus. Hispania 75(4)4 (October 1992): 828-35.

Athanassakis, Apostolos N., Translator and editor. Hesiod: Theogony. Works and Days. Shield. Baltimore and London: The Johns Hopkins University Press, 1983.

Atkinson, Geoffroy. Les nouveaux horizons de la Renaissance francaise. Paris: E. Droz, 1935.

Bandini, Angelo Maria. Vita e Lettera di Amerigo Vespucci. Florence: Apollo, 1745.

Bernheimer, Richard. The Wild Man in the Middle Ages: A Study in Art, Sentiment, and Demonology. New York: Octagon Books, 1970.

Colón, Cristóbal. Los cuatro viajes del Almirante y su testamento. Ignacio B. Anzoátegui, editor. Madrid: Espasa-Calpe, 1986.

Defaux, Gérard. Un cannibale en haut de chausses: Montaigne, la différence et la logique de l'identité. Modern Language Notes 7/4 (May 1982): 919-57.

Erickson, Carolly. The Medieval Vision: Essays in History and Perception. New York: Oxford University Press, 1976.

Gerbi, Antonello. Nature in the New World: From Christopher Columbus to Gonzalo Fernández de Oviedo. Jeremy Moyle, translator. Pittsburgh: University of Pittsburgh Press, 1985.

Gibbon, Edward. The English Essays. Patricia B. Craddock, editor. Oxford: Clarendon Press, 1972.

Hanke, Lewis. Aristotle and the American Indians: A Study in Race Prejudice in the Modern World. London: Hollis and Carter, 1959.

The Theological Significance of the Discovery of America. First Images of America: The Impact of the New World on the Old Vol. I. Fredi Chiapelli, editor. Berkeley, Los Angeles and London: University of California Press, 1976. 363-90.

Hardison, O. B. et al., translator and editor. General Introduction. Medieval Literary Criticism: Translations and Interpretations. New York: Frederick Ungar, 1974.

Hartog, François. Le Mirroir d' Hérodote: Essai sur la représentation de l'autre. Paris: Gallimard, 1980.

Hazlitt, W. Carew, editor. Of Cannibals. The Essays of Michel de Montaigne Vol. I. Charles Cotton, translator. New York: A. L. Burt, 1892. 
Hodgen, Margaret. Early Anthropology in the Sixteenth and Seventeenth Centuries. Philadelphia: University of Pennsylvania Press, 1964.

Holanda, Sérgio Buarque de. Visão do Paraiso: Os Motivos Edênicos nos Descobrimentos e Colonizacão do Brasil. São Paulo: Companhia Editora Nacional, 1969.

Lestringant, Frank. Le cannibalisme des 'Cannibales', I. Montaigne et la tradition. Bolletin de la Société des Amis de Montaigne 9-10 (1982a): 27-40.

Le cannibalisme des 'Cannibales', II. De Montaigne à Malthus. Bolletin de la Société des Amis de Montaigne 11-12 (1982b): 19-38.

Le Nom de 'Cannibales' de Christophe Colomb à Michel de Montaigne. Bulletin de la Société des Amis de Montaigne 17-18 (1984): 51-74.

Levin, Harry. The Myth of the Golden Age in the Renaissance. New York: Oxford University Press, 1972.

Lovejoy, Arthur and George Boas. Primitivism and Related Ideas in Classical Antiquity. New York: Octagon Books, 1965.

Manfroni, Camilo, editor. Relazione del primo viaggio intorno al mondo di Antonio Pigafetta. Milan: Alpes, 1977.

Mariotti, Giovanni, editor. I Cannibali. Gianni Guadalupi et al, editores. Milano: Franco Maria Ricci Editore, 1977.

Mayor, J. E. B., editor. Thirteen Satires of Juvenal II. London: Hildesheim, 1888.

McIlwain, Charles Howard. The Growth of the Political Thought in the West: From the Greeks to the End of the Middle Ages. New York: Macmillan, 1953.

Miner, Earl, Hayden White et al. The Wild Man Within: An Image in Western Thought from the Renaissance to Romanticism. Edward Dudley and Maximillian E. Novak, editores. Pittsburgh: University of Pittsburgh Press, 1972.

Montaigne, Michel de. Of Cannibals. Essays [1580] Vol. I. Charles Cotton, translator. W. Carew Hazlitt, editor. New York: A. L. Burt Co. Publishers, 1892. 207-21.

Morse, Richard M. Toward a Theory of Spanish American Government. Journal of the History of Ideas 15/1 (January 1954): 71-93.

O'Gorman, Edmondo. The Invention of America. Bloomington: IndianaUniversity Press, 1961.

Pigafetta, Antonio. The First Voyage Round the World by Magellan. Lord Stanley of Alderley, editor. London: Hakluyt Society, 1874.

Pupo-Walker, Enrique. La vocación literária del pensamiento histórico en América. Madrid: Editorial Gredos, 1982.

Quinn, David B. New Geographical Horizons: Literature. First Images of America: The Impact of the New World on the Old Vol. I (1976): 635-58. Fredi Chiapelli, editor. Berkeley, Los Angeles and London: University of California Press, 1976.

Rose, K. F. C. The Date and the Author of the Satyricon. Netherlands: E. J. Brill, 1971.

Sauer, Carl Ortwin. The Early Spanish Main. Berkeley, Los Angeles and Oxford: University of California Press, 1992.

Scaglioni, Aldo. A Note on Montaigne's 'Des Cannibales' and the Humanist Tradition. First Images of America: The Impact of the New World on Old Vol. I. Fredi Chiapelli, editor. Berkeley, Los Angeles and London: University of California Press, 1976. 63-70. 
Seaford, Richard, editor. Euripedes: Cyclops. Oxford: Clarendon Press, 1984.

Sepúlveda, Juan Ginés de. Tratado sobre las justas causas de la guerra contra los Indios. México: Fondo de Cultura Económica, 1941.

Simões, Manuel. A Literatura de Viagens nos Séculos XVI e XVII. Lisboa: Editorial Comunicações, 1985.

Slavitt, David R., translator and editor. Sêneca: The Tragedies Vol. I. Baltimore and London: The Johns Hopkins University Press, 1992. 45-83.

Staden, Hans. Duas Viagens ao Brasil. Guiomar de Carvalho Franco, translator. São Paulo: Editora da Universidade de São Paulo, 1974.

Stock, Brian. Myth and Science in the Twelfth Century. Princeton: Princeton University Press, 1972.

Stoetzer, O. Carlos. The Scholastic Roots of the Spanish American Revolution. New York: Fordham University Press, 1979.

Sullivan, J. P. The Satyricon of Petronius: A Literary Study. London: Faber and Faber, 1968.

Todorov, Tzvetan. The Conquest of America: The Question of the Other. Richard Howard, translator. New York: Harper and Row Publishers, 1984.

Turner, Paul, editor. Introduction. The History of the World Commonly Called the Natural History ofC. Plinius Secundus. Tradutor Philemon Holland. Carbondale: Southern Illinois University Press, 1962.

Villoro, Luis. 1950. Los grandes momentos del indigenismo en México. México: Colegio de México. Microfilm: University of Texas Library (Austin), 1950.

Weinberg, Bernard. Montaigne's Reading for 'Des Cannibales'. Renaissance and Other Studies in Honor of William Leon Wiley. Chapel Hill: University of North Carolina Press, 1968.

Wetherbee, Winthrop. Platonism and Poetry in the Twelfth Century: The Literary Influence of the School of Chartres. Princeton: Princeton University Press, 1972.

Whatley, Janet, translator and editor. Introduction. Jean de Léry, History of a Voyage to the Land of Brazil. Otherwise Called America. Berkeley and Los Angeles: University of California Press, 1990.

White, Hayden. The Forms of Wildness: Archaeology of an Idea. Tropics of Discourse: Essays in Cultural Criticism. Baltimore and London: The Johns Hopkins University Press, 1992. 
